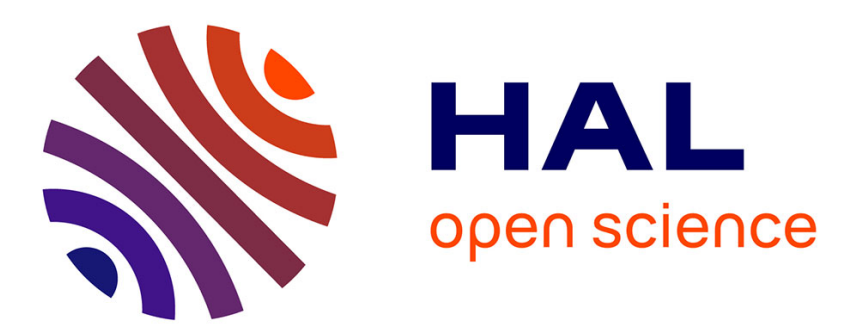

\title{
Transboundary Pollution in the Black Sea: Comparison of Institutional Arrangements
}

Basak Bayramoglu

\section{To cite this version:}

Basak Bayramoglu. Transboundary Pollution in the Black Sea: Comparison of Institutional Arrangements. Environmental and Resource Economics, 2006, 35, pp.289-325. 10.1007/s10640-006-9016-0 . hal-01514234

\section{HAL Id: hal-01514234 \\ https://hal.science/hal-01514234}

Submitted on 25 Apr 2017

HAL is a multi-disciplinary open access archive for the deposit and dissemination of scientific research documents, whether they are published or not. The documents may come from teaching and research institutions in France or abroad, or from public or private research centers.
L'archive ouverte pluridisciplinaire HAL, est destinée au dépôt et à la diffusion de documents scientifiques de niveau recherche, publiés ou non, émanant des établissements d'enseignement et de recherche français ou étrangers, des laboratoires publics ou privés.

\section{다(1)(2)}

Distributed under a Creative Commons Attribution - ShareAlikel 4.0 International 


\title{
Transboundary Pollution in the Black Sea: Comparison of Institutional Arrangements
}

\author{
Basak BAYRAMOGLU* \\ PSE (Paris-Jourdan Sciences Economiques) and \\ EUREQua-Université Paris1 Panthéon-Sorbonne. \\ Ceras, ENPC, 28 rue des Saints-Pères, 75343 Paris cedex 07 France \\ (e-mail : basak.bayramoglu@enpc.fr)
}

September 2005

\begin{abstract}
This paper analyses the transboundary pollution between Romania and Ukraine, coastal states along the Black Sea, and studies the welfare consequences of institutional arrangements for controlling this problem. To achieve this goal, we use a dynamic and strategic framework. We compare in terms of total welfare for two countries a first-best case with three different institutional arrangements: the non-cooperative game of countries, the uniform emission policy and the constant emission policy as proposed by the Black Sea Commission. Our findings indicate that the noncooperative game provides a better level of total welfare than the other rules.

Keywords: Black Sea, dynamic games, environment, institutional arrangements, noncooperative games, transboundary pollution, water pollution.

JEL: C72, C73, Q5, Q53.
\end{abstract}

\footnotetext{
${ }^{*}$ I would like to thank Jean-François Jacques and Mireille Chiroleu-Assouline for their valuable help on this work. I am also grateful to Sema Acar, Ivar Ekeland, Rafal Kierzenkowski and Philippe Picon for their constructive comments. I would like to thank the participants of the seminars at the EUREQua-University Paris-1, Paris (March 2003), the METU 2003 International Congress on Economics, Turkey (September 2003), the LEI-CREST, Paris (December 2003), the EAERE, Budapest (June 2004) and the AFSE, Paris (September 2004), especially Bernard Salanié and Jérôme Pouyet for their helpful comments. I am indebted to two anonymous referees for very helpful comments. Any errors are the responsibility of the author.
} 


\section{Introduction}

This paper deals with the problem of transboundary pollution in the Black Sea and asks whether cooperation is needed to agree on an optimal level of pollution. The Black Sea is the largest semi-enclosed anoxic basin in the world. In this sea, the most significant pollution problem has been identified as the eutrophication ${ }^{1}$ phenomenon. This problem affects Romania and Ukraine, more than the other coastal countries (Bulgaria, Russia, Georgia and Turkey). The eutrophication of the Black Sea due to excessive loads of nutrients via the rivers and coming directly from the coastal countries has led to radical changes in the ecosystem since the 1960s. Oxygen deficiency (hypoxia or anoxia) and mass mortality caused by eutrophication have become a permanent feature in the north-western shelf area where anoxic zones have expanded from covering $3500 \mathrm{~km}^{2}$ in 1973 to $40000 \mathrm{~km}^{2}$ in 1990 (Zaitsev et al., (2002)). This has had a major transboundary impact on biological diversity and human use of the sea, including fisheries, tourism and recreation.

The nitrogen and phosphorus compounds that trigger eutrophication come from all over the Black Sea Basin. The Black Sea Transboundary Diagnostic Analysis (1996) indicates that in 1992, $70 \%$ of the nutrients came from the six Black Sea countries. We will concentrate our attention on two coastal countries of the Black Sea, Romania and Ukraine which have an individual contribution of $27 \%$ and $12 \%$ of nitrogen to the sea, respectively (Transboundary Diagnostic Analysis (1996)). These two are also the coastal countries most affected by the eutrophication phenomenon. The depth of the north-western part of the Black Sea is largely below one hundred meters. It constantly receives a large supply of nutrients from the Danube and Dnieper rivers, which are the second and third largest rivers in Europe (Mee, (2002)). Consequently, Romania and Ukraine are both the sources and the victims of this pollution problem. Thus, it is logical to focus on these two countries to study the nutrient pollution on the north-western coast of the Black Sea.

Nutrient pollution, the problem of over-exploitation of fishery resources, the introduction of exotic species (such as the Mnemiopsis Leidyi, introduced in 1982) and the modifications in river flow regimes have resulted in a decrease in the diversity of commercial fish from some 26 species to only six, since the late 1970s (Zaitsev

\footnotetext{
${ }^{1}$ Eutrophication means an over-enrichment of the water bodies with organic matter, especially algae (phytoplankton). The algae grow in all surface waters when there is enough light and essential nutrients, especially nitrogen and phosphorus. When the nutrient level is too high, it supports over abundant plankton production. When the plankton degrades, the oxygen consumption increases to undesired levels, and the undesirable changes in water quality can lead to the extinction of species. In the Black Sea, this has already happened and the food chain has been seriously disrupted.
} 
et al., (2002)). Thus, we will study one of these factors causing the deterioration of fish resources: nutrient-type pollution. There is not enough evidence to relate most pollutants to the decline of fisheries. In the case of eutrophication, however, there is clearly a loss of habitat and food for some kinds of fish (Mee, (2002)). The nutrient-type pollution can arise from agricultural and industrial activities or from domestic emissions. A study on the Danube River basin countries showed that the agricultural sector was responsible for $50 \%$ of nutrient emissions, while industry and the urban sector both had shares of $25 \%$ (Saving the Black Sea, (2002)). Therefore, our study will concentrate on agricultural activities with adverse effects on fishery resources.

The deterioration of fishery resources from the late 1970s to the 1990s shows that the eutrophication problem is a long-term phenomenon, which has obliged us to use a dynamic model to explain it. Strategic interactions exist between countries, which led us to use a game model. Each country thinks that the other country will reduce its emissions when the total stock of pollution is high. As each country has the same reasoning, the final result is not a first-best outcome.

Transboundary pollution occurs when a country's emissions negatively affect other countries (negative spillovers). In areas such as global warming, ozone- layer depletion, acid rain or international water pollution, these negative effects are not taken into account by the polluting countries. The largest part of the transboundary pollution literature is devoted to the issue of a coalition formation between countries for signing an international environmental agreement. The number of signatories and the stability of the agreement have been analyzed (see among others Barrett (1994), Hoel (1991), Carraro and Siniscalco(1993)). The other part of the transboundary pollution literature is related to dynamic games, particularly to differential games ${ }^{2}$. For instance, Chander and Tulkens (1995) apply a cooperative game theory concept (core solution) to a dynamic context in order to study international negotiations in the area of transboundary pollution.

The dynamic evolution of the pollution stock, a phenomenon that is ignored in the repeated games framework, is taken into account by differential games. There are a number of applications of differential games to pollution economics (see among others Maler and de Zeeuw (1998), Feenstra, Kort and de Zeeuw (2001)) $)^{3}$. For instance, the differential game model of List and Mason (2001) analyses the efficiency

\footnotetext{
${ }^{2}$ See Missfeldt (1999) for a survey on the game-theory modeling of transboundary pollution problems.

${ }^{3}$ There are also a number of applications of differential games to resource economics (see for instance Karp (1992), Mason and Polasky (1997) and Mason and Polasky (2002)).
} 
of different institutional arrangements in the presence of transboundary pollution between two countries. Their result shows the possible efficiency of decentralized policy when the countries are sufficiently heterogeneous.

The empirical analysis of transboundary water pollution problems has not yet been expanded. One of the exceptions is Fernandez's (2002) paper on the analysis of transboundary water pollution between Mexico and the United States within an interconnected and differential games framework. The author shows that trade liberalization between the two countries gives the necessary incentives to Mexico, which produces cotton and exports it to the U.S., to abate its emissions, and thus reduce transboundary pollution. Cooperation on environmental control between two countries enforces this result. There are also few papers on the theoretical and empirical analysis of nutrient pollution in the Baltic Sea, which is also an international water body. Gren and Folmer's paper (2002) takes into account the inherent uncertainty related to damage from nitrogen emissions in the Baltic Sea. They established that when the risk aversion is high, the abatement is high and the net benefits of abatement are low. This result holds for the cooperative and the non-cooperative solutions. Gren's paper (2001) studies the eutrophication phenomenon in the Baltic Sea. The empirical results show that total net benefits under internationally coordinated actions are higher than when countries act on their own. Both specifications of net benefits, uniform or differentiated, under international coordination, allow higher total benefits than those of national actions.

To the best of our knowledge, there is only one case study on the pollution problem in the Black Sea in the area of environmental economics; it is by Knowler, Barbier and Strand (1997). They study the detrimental effects of excessive nutrient loads on commercial fisheries in the Black Sea. The paper focuses on the long-run implications of pollution abatement policies for open-access fisheries using a dynamic bioeconomic model that integrates nutrient loads into the natural production function that governs the growth of anchovy stocks.

Our paper focuses on the comparison of institutional arrangements in terms of total welfare for countries. Although largely inspired by the model of List and Mason (2001), our paper presents some extensions. First, our model uses a payoff function, which explicitly shows the trade-off between agricultural and fish production activities. Secondly, our model specifies the loss of fish revenues due to the pollution stock generated by agriculture, thus it is most appropriate to studying the specific pollution problem at the north-western corner of the Black Sea. Finally, our paper studies the implications in terms of welfare of a first-best allocation case for a comparison in terms of possible transfers with other second-best outcomes. We are 
also interested in evaluating a policy proposed by the Black Sea Commission which consists in maintaining countries' 1997 emission levels.

In this paper, we consider one first-best and three alternative second-best outcomes ${ }^{4}$. In the first-best solution, a central authority (for instance a supranational institution) that knows without uncertainty the characteristics of countries chooses a level of emission specific to each country in order to maximize the total welfare of these countries. In one of the second-best outcomes, the same central authority implements uniform emission standards for both countries. This will not represent the first-best outcome if preferences, emission and damage functions are different between countries. In the other second-best outcome, countries have the possibility of choosing different emission levels that maximize their own welfare. This is not a first-best solution because of the coordination failure. Finally, we offer an evaluation of the policy proposed by the Black Sea Commission. This policy is also not a firstbest solution because it doesn't arise from an optimization calculus. The different size of the populations of Romania and Ukraine also leads us to evaluate per capita emission standards, especially the per capita uniform emission policy.

This paper addresses the following issue: what is the best institutional arrangement in terms of total (for two countries) welfare for regulating the pollution problem between Romania and Ukraine?

The paper is organized as follows. Section 2 presents a linear quadratic game. We determine different equilibria consisting of different institutional arrangements, including the policy proposed by the Black Sea Commission and the per capita uniform emission policy, in Section 3. In Section 4, we describe the empirical data. We illustrate the model with a numerical application in Section 5 and offer concluding remarks in section 6 .

\section{The Model}

The preferences of agents of a specific country are represented by the following utility function:

$$
U(A, F)=\alpha_{1} A-\frac{\alpha_{2}}{2} A^{2}+\beta_{1} F-\frac{\beta_{2}}{2} F^{2}
$$

where $A$ and $F$ denote the agricultural good consumption and fish good consumption respectively. This utility function has a quadratic form, and it is additively

\footnotetext{
${ }^{4}$ The analysis of two second-best outcomes is in line with List and Mason's analysis (2001).
} 
separable. The parameters $\alpha_{1}, \alpha_{2}, \beta_{1}$ and $\beta_{2}$ are positive.

The agricultural production function can be written as:

$$
A=a N_{A}
$$

where $N_{A}$ represents the labor force in the agricultural sector of a specific country and $a$ is the agricultural productivity parameter for this country.

Similarly, the fish production function in the sense of a Schaefer function is assumed to be:

$$
F=\bar{S} f N_{F}-\bar{S} \gamma P
$$

where $^{5} N_{F}$ is the labor force in the fishery sector of a specific country, $f$ is constant fishery productivity parameter and $\bar{S} f$ is the fishery productivity for that country $^{6}$ given that $\bar{S}$ is the stationary level of the fish stock in a given "patch" at time $t$. We assume that $\bar{S}$ is constant through time. ${ }^{7} 8$

Here, we are inspired by the patchy population story concerning fish resources (Sanchirico and Wilen (1999)). The authors underline the importance of taking into account the implications of space because real fish populations are heterogeneously distributed across space. Their dynamic model incorporates the density-dependent growth rate of fish species and the density-dependent dispersal between patches. The idea is that when the fish biomass is lower than its carrying capacity, two

\footnotetext{
${ }^{5} \mathrm{~A}$ Schaefer function in the fishery resource literature is $F=e E S$ where $E$ is the effort level, $S$ is the fish stock and $e$ is the productivity parameter. In our function, we additionally have the negative effect of the pollution stock on the fish stock, which is the specificity of the eutrophication phenomenon.

${ }^{6}$ The fishery resources literature considers that the growth rate of fishery resources depends on the existing fish stock. In this model, however, we assume the constancy of the parameter $\bar{S} f$, i.e. that we are always on the stationary fish stock level. Otherwise, we should include another state variable describing the evolution of the fish stock.

${ }^{7}$ We use the same definition of a patch as assumed by Sanchirico and Wilen (1999) A patch is a location in space that contains or has the potential to contain an aggregation of biomass (p.131).

${ }^{8}$ The ideal specification for the fish production function would be the following one:

$$
F=\bar{F}-\gamma P f N_{F}=\bar{S} f N_{F}-\gamma P f N_{F}
$$

where there is a loss of a certain amount of the fish stock because of the existing pollution stock. But this expression of $F$ in our original utility function gives rise to additional polynomial terms in $E$ and $P$. This problem would become untractable in a linear-quadratic framework. To avoid this problem, we use an alternative formulation for the actual harvest function $F$.
} 
effects will be in place: the own growth rate of fish population and the dispersal from other patches will together bring the fish biomass in each patch to its carrying capacity in the long-run.

We assume in this model that each country's zone in the sea represents a different patch. We consider the movement of fish species between the two patches. At the stationary fish stock level $\bar{S}$, the system is assumed to be in a space-time steady state. Hence, fish species are unchanging over time and there is no movement for fish species between different patches, such that the fish population in each patch is stabilized. For simplicity, we assume that the stationary fish stock in each patch only depends on the total pollution stock of Romania and Ukraine and not on the pollution stock of the other coastal countries. This is not an unrealistic assumption since the eutrophication phenomenon is a very localized pollution problem at the north-western part of the sea.

We can express the above function in a different way:

$$
F=\bar{F}-L
$$

where $\bar{F}=\bar{S} f N_{F}$ is the potential harvest, $L=\bar{S} \gamma P$ is the fishery resource loss, both positively depending on the stationary level of the fish stock $\bar{S}$. The total pollution stock $P$ negatively affects the fish stock in a given patch. The parameter $\gamma$ explains the magnitude with which an increase in the pollution stock adversely affects the quantity of the fish. Since we have the data on the fishery resource loss for each country $L$ as well as on the total pollution stock $P$, we can obtain an evaluation of the fishery loss parameter:

$$
\bar{S} \gamma=\frac{L}{P}
$$

We assume that $N_{A}+N_{F}=\bar{N}$ where $\bar{N}$ is the exogenous available labor force in a country.

We assume that agricultural production leads to emissions, which can be represented by the following function:

$$
E=c+\frac{1}{\mu} A
$$

where $E$ represents the emissions of a given country caused by its agricultural production $A$ and $\mu$ is the inverse of the emission parameter. We assume that 
the countries have the same emission parameter $\left(\frac{1}{\mu}\right)$ but different fixed emission components $c$. The identity of the emission parameters is needed because the countries could have similar agricultural technologies. The difference in fixed emission components $c$ could be explained by the different distance between the agricultural production and the coastal place where the pollution measurement is made. Hence, the emission levels for the two countries can vary.

This expression of the actual harvest $F=\bar{S} f\left(\bar{N}+\frac{\mu}{a} c\right)-\bar{S} f \frac{\mu}{a} E-\bar{S} \gamma P$ in our original utility function now gives rise to linear-quadratic terms in $E$ and $P$ and allows the use of the linear-quadratic solution for the differential game.

If we replace the above expressions of the agricultural production and the fish production in the utility function, we obtain:

$$
\begin{aligned}
U(A, F)= & \alpha_{1}(\mu(E-c))-\frac{\alpha_{2}}{2}(\mu(E-c))^{2} \\
& +\beta_{1}\left(\bar{S} f\left(\bar{N}+\frac{\mu}{a} c\right)-\bar{S} f \frac{\mu}{a} E-\bar{S} \gamma P\right) \\
& -\frac{\beta_{2}}{2}\left(\bar{S} f\left(\bar{N}+\frac{\mu}{a} c\right)-\bar{S} f \frac{\mu}{a} E-\bar{S} \gamma P\right)^{2}
\end{aligned}
$$

If we develop and rearrange the above expressions in parentheses, we obtain the following form for the utility function of the country $i$ :

$$
U_{i}=e_{i}+a_{i} E_{i}-\frac{f_{i}}{2} E_{i}^{2}-c_{i} P-\frac{b_{i}}{2} P^{2}+d_{i} E_{i} P
$$

where

$$
\begin{aligned}
& e_{i}=\beta_{1} \bar{S} f\left(\bar{N}+\frac{\mu}{a} c\right)-\frac{\beta_{2}}{2} \bar{S}^{2} f^{2}\left(\bar{N}+\frac{\mu}{a} c\right)^{2}-\alpha_{1} \mu c-\frac{\alpha_{2}}{2} \mu^{2} c^{2} \\
& a_{i}=\alpha_{1} \mu+\alpha_{2} \mu^{2} c-\beta_{1} \bar{S} f \frac{\mu}{a}+\beta_{2} \bar{S}^{2} f^{2} \frac{\mu}{a}\left(\bar{N}+\frac{\mu}{a} c\right) \\
& f_{i}=\alpha_{2} \mu^{2}+\beta_{2} \bar{S}^{2} \frac{\mu^{2}}{a^{2}} f^{2} \\
& b_{i}=\beta_{2} \bar{S}^{2} \gamma^{2} \\
& c_{i}=\beta_{1} \bar{S} \gamma-\beta_{2} \bar{S}^{2} f \gamma\left(\bar{N}+\frac{\mu}{a} c\right) \\
& d_{i}=\beta_{2} \bar{S}^{2} \frac{\mu}{a} f \gamma
\end{aligned}
$$

Finally, we will consider the following equation which explains the evolution of the pollution stock: 


$$
\stackrel{\bullet}{P}=E_{i}+E_{j}-k P
$$

where $E_{i}$ and $E_{j}$ represent emission levels of the countries $i$ and $j$, and $k$ is the natural purification rate of pollution.

In the next section, we will determine equilibria associated with different institutional arrangements.

\section{The Characterization of the Equilibria}

First, we will consider the non-cooperative game where each country has the possibility of choosing different levels of emission abatement with the behavior of the other country taken as given. In the appendix, we exhaustively represent the resolution of a non-cooperative game where there are explicitly strategic interactions between two countries. The similar resolution of the uniform emission policy and the first-best outcome (both with no strategic interactions) will not be shown in detail.

The non-cooperative game

The maximization problem of country $i$ is:

$$
\begin{aligned}
\underset{E_{i}}{\operatorname{Max}} \int_{0}^{\infty} e^{-r t} U_{i} d t \\
\dot{P}=E_{i}+E_{j}-k P
\end{aligned}
$$

where $U_{i}$ represents the country $i$ 's instantaneous utility function and $r$ its discount factor.

Here, we assume that the countries use feedback Nash strategies. In this case, the countries condition their control variables (here, the emission levels) on the current state of the system (here, the current level of the pollution stock). This implies that they indirectly take into account the reaction function of the other country, which is conditioned by the evolution of the pollution stock. This type of Nash equilibrium implies that the control variables are a function of time as well as of the current state of the system. The resulting equilibrium is subgame perfect. In the case of the open-loop Nash equilibrium, the agents commit to their strategies at the beginning of the game. They chose their strategies for the whole time period and do not revise them whenever new information appears. This type of Nash equilibrium 
implies that the control variables are only a function of time. If the countries can condition their strategies on the current state as well as on the past states of the system, closed-loop Nash equilibria can be non-unique.

In the presence of the feedback Nash equilibria, country $i$ takes into account the reaction function of country $j$ to its decision on its own program. Country $j$ acts in the same way. The reaction of country $j$ (its emissions $E_{j}$ ) are conditioned by the evolution of the pollution stock $P$, which depends on country $i$ 's decision $\left(E_{i}\right){ }^{9}$

The Hamiltonian related to this problem can be denoted:

$$
\begin{aligned}
H\left(E_{i}, P, \lambda_{i}\right)= & {\left[e_{i}+a_{i} E_{i}-\frac{f_{i}}{2} E_{i}^{2}-c_{i} P-\frac{b_{i}}{2} P^{2}+d_{i} E_{i} P\right] } \\
& +\lambda_{i}\left(E_{i}+E_{j}-k P\right)
\end{aligned}
$$

where $\lambda_{i}$ represents the shadow variable associated with the evolution of the pollution stock.

The first-order conditions are the following:

$$
\begin{gathered}
\frac{\partial H}{\partial E_{i}}=0 \Longleftrightarrow \lambda_{i}=f_{i} E_{i}-d_{i} P-a_{i} \\
\dot{\lambda_{i}}=r \lambda_{i}-\frac{\partial H}{\partial P} \Longleftrightarrow \dot{\lambda}_{i}=r \lambda_{i}+b_{i} P+c_{i}-d_{i} E_{i}+\lambda_{i} k-\lambda_{i} \frac{\partial E_{j}}{\partial P}
\end{gathered}
$$

The term $\lambda_{i} \frac{\partial E_{j}}{\partial P}$ shows the fact that country $i$ takes into account the reaction of country $j$ to the common pollution stock.

Because the problem is of a linear-quadratic nature, we search for a solution so that the shadow variable, and, naturally, the emission level, are linear functions of the state variable $(P)^{10}$ :

${ }^{9}$ The resolution method of differential games can be either dynamic programming, as proposed by List and Mason (2001), or intertemporal optimization as proposed by Fudenberg and Tirole (1991). It is possible to show the equivalence of these two methods. Nevertheless, we have decided to use Fudenberg and Tirole's method since they do not eliminate the time index in their resolution (Fudenberg and Tirole,1991, p.523).

${ }^{10}$ The resolution method suggested by Fudenberg and Tirole does not include a crossed term on the choice and stock variables in the utility function, whereas this term exists in our utility function. But it is possible to show that the resolution method also fits with the existence of this additional term, by a variable change. Hence, the introduction of a crossed term on the choice and state variables does not the change the nature of the linear-quadratic differential game. I am grateful to Ivar Ekeland for pointing me out this property. 


$$
\lambda_{i}=\delta_{i} P+\varepsilon_{i}
$$

where $\delta_{i}$ and $\varepsilon_{i}$ are parameters and $P$ is the pollution stock. For the existence and stability of equilibrium, the parameter $\delta_{i}$ should be negative.

If we solve the program for both countries $i$ and $j$, we obtain the following form of total value function, $V_{N C}$, defined as the sum of the optimal values of the objective functions:

$$
V_{N C}=V_{i}+V_{j}=\frac{1}{r}\left(z_{1}^{i}+z_{1}^{j}\right)+\frac{1}{r-w}\left(z_{2}^{i}+z_{2}^{j}\right)+\frac{1}{r-2 w}\left(z_{3}^{i}+z_{3}^{j}\right)
$$

where $w=\frac{\delta_{i}+d_{i}}{f_{i}}+\frac{\delta_{j}+d_{j}}{f_{j}}-k$ ( $k$ being the self-purification rate of pollution) and $z_{1}, z_{2}, z_{3}$ are constant parameters depending on the fundamental parameters. We assume that $-r+w<0$ and $-r+2 w<0$.

We can ask if a supranational authority can implement a uniform emission standard for the two countries instead of "laisser-faire". The use of a common emission standard could be linked to the following argument. The regulator could only have information based on an average for the characteristics of each country. In this case, the regulator would be able to evaluate the distribution of the characteristics of the countries whereas in the first-best case, he would know with certainty the countries' individual characteristics.

\section{The uniform emission policy}

In the uniform emission policy, the regulator chooses a uniform emission level which maximizes the total welfare of the countries. Thus, the program is:

$$
\begin{aligned}
\underset{E}{\operatorname{Max}} \int_{0}^{\infty} e^{-r t} U d t \\
\dot{P}=2 E-k P
\end{aligned}
$$

where $U$ is the sum of the instantaneous utility functions of the two countries, under the assumption that the constraint is binding:

$$
\begin{aligned}
U= & U_{i}+U_{j}=\left(e_{i}+e_{j}\right)+\left(a_{i}+a_{j}\right) E-\left(\frac{f_{i}+f_{j}}{2}\right) E^{2} \\
& -\left(c_{i}+c_{j}\right) P-\left(\frac{b_{i}+b_{j}}{2}\right) P^{2}+\left(d_{i}+d_{j}\right) E P
\end{aligned}
$$


The difference between the uniform emission policy and the non-cooperative game can be seen in these formulations. The regulator implements the same emission standard $E$ for both countries $i$ and $j$ in the centralized (uniform emission, $E_{i}=$ $E_{j}$ ) system, while in the decentralized (non-cooperative) system, countries have the possibility of choosing an emission level that maximizes their own welfare.

Now, we will turn to the first-best outcome, which will form the benchmark case. Here a regulator, endowed with perfect information on the characteristics of the countries, chooses a level of emission specific to each country, which maximizes the total welfare of these countries.

\section{The first-best outcome}

In the first-best solution (which forms the benchmark case), the regulator chooses a level of emission specific to each country which maximizes the total welfare of these countries. Thus, the program is:

$$
\begin{aligned}
& \underset{E_{i}, E_{j}}{\operatorname{Max}} \int_{0}^{\infty} e^{-r t} U d t \\
\dot{P}= & E_{i}+E_{j}-k P
\end{aligned}
$$

where $U$ is the sum of the instantaneous utility functions of the two countries:

$$
\begin{aligned}
U= & U_{i}+U_{j}=\left(e_{i}+e_{j}\right)+a_{i}\left(E_{i}\right)+a_{j}\left(E_{j}\right)-\frac{f_{i}}{2}\left(E_{i}^{2}\right)-\frac{f_{j}}{2}\left(E_{j}^{2}\right) \\
& -\left(c_{i}+c_{j}\right) P-\left(\frac{b_{i}+b_{j}}{2}\right) P^{2}+d_{i}\left(E_{i} P\right)+d_{j}\left(E_{j} P\right)
\end{aligned}
$$

Now, we will look at the policy proposed by two different commissions for the Black Sea pollution problem. It consists in maintaining, for each country, its emission level of 1997.

The Common Policy Proposed by the Black Sea Commission and International Commission on the Protection of the Danube River

The Global Environmental Facility (GEF) provided assistance to the Black Sea Commission (BSC) and the International Commission on the Protection of the River Danube (ICPDR) to study the causes and impacts of eutrophication in the Black Sea and to recommend a common strategy. The scientists and the two commissions agreed on the following: 
The long-term goal for all Black Sea basin countries is to take measures to reduce nutrient levels and other hazardous substances to such a level as to permit the Black Sea ecosystems to recover to similar conditions as those observed in the 1960s... As an intermediate goal, urgent control measures should be taken by all countries in the Black Sea basin in order to prevent discharges of nitrogen, phosphorus and other hazardous substances into the Black Sea exceeding those levels observed in $\mathbf{1 9 9 7}$ (Saving the Black Sea, (2002)).

This policy recommendation is widely based on the measures of the average emissions made during one year (1996-1997) by the Transboundary Diagnostic Analysis, (1996).

We can try to evaluate the 1997 policy, which is an urgent measure to reduce nutrients, based on the freezing of each country's current emissions to their 1997 levels. We can imagine a situation where countries have started implementing this policy since 1979 , i.e. the date of our initial pollution stock.

This policy leads to the following global welfare:

$$
\int_{t=0}^{\infty} e^{-r t}\left(U_{1}+U_{2}\right) d t
$$

where

$$
U_{i}=e_{i}+a_{i} E_{i}-\frac{f_{i}}{2} E_{i}^{2}-c_{i} P-\frac{b_{i}}{2} P^{2}+d_{i}\left(E_{i} P\right)
$$

for $i=1,2$.

Our data on Romanian and Ukrainian emissions and the pollution stock in 1997 are the following: $E_{1}$ (Romania, 1997): 9840, $E_{2}$ (Ukraine, 1997): 4373, Total Emissions: 14213 and $P$ (1979): 49500.

By solving the above integral with $P(t)=\left(P_{0}-\frac{E_{1997}}{k}\right) \times e^{-k t}+\frac{E_{1997}}{k}$ where $P_{0}=P(1979)$, we can obtain an evaluation of the 1997 policy in terms of the total welfare for the countries and compare it with the other three regimes.

We can also take into account the differences in population size of Romania and Ukraine and evaluate the efficiency of per capita emission standards, and especially of the per capita uniform emission policy.

\section{Per capita emission standards}

To consider a part of the asymmetry between the countries, we introduce a parameter $T$ which is the ratio of the populations of the two countries ${ }^{11}$ :

\footnotetext{
${ }^{11}$ Source: CIA world factbook: www.cia.gov/cia/publications/factbook/
} 


$$
T=\frac{\text { Pop }_{2}}{\text { Pop }_{1}}=\frac{47425336(2005 \text { estimated })}{22329977(2005 \text { estimated })}=2,12
$$

Here, the indexes 1 and 2 respectively indicate Romania and Ukraine. We observe that the population size of Ukraine is more than twice that of Romania. This indicates the importance of taking into account the population size differences of the countries when evaluating the efficiency of different regimes, especially the uniform emission policy. ${ }^{12}$

The uniform emission policy naturally implies the equality of the emission levels for the countries:

$$
\frac{E_{1}}{P_{o p_{1}}}=\frac{E_{2}}{\text { Pop }_{2}} \Longleftrightarrow E_{1}=\frac{P_{o p_{1}}}{\text { Pop }_{2}} E_{2} \Longleftrightarrow E_{1}=\frac{1}{T} E_{2}
$$

We note $E_{2}=E$.

The program in the uniform emission policy becomes:

$$
\begin{aligned}
& \max _{E} \int\left[U_{1}\left(\frac{E}{T}, P\right)+T U_{2}(E, P)\right] e^{-r t} d t \\
\dot{P}= & \frac{E}{T}+E-k P=\frac{E(1+T)}{T}-k P
\end{aligned}
$$

In the next section, we will describe ecological and economic data related to Romania and Ukraine.

\section{The Data for Romania and Ukraine}

We have used several sources of information to obtain some benchmark values of the parameters. Data and information have been extracted from: Datastream Data Base; World Bank Development Indicators; IMF External Publications; Black Sea Environmental Programme; Food and Agriculture Organization; The State of the Environment of the Black Sea: Pressures and Trends 1996-2000; Annual Statistics of Romania (2001); OECD Statistics (2003); Implementation of the Strategic Action Plan for the Rehabilitation and Protection of the Black Sea (1996-2001). The reader can refer to the appendix for the construction of the data.

\footnotetext{
${ }^{12}$ See the appendix for the programs with the per capita emission standards in the noncooperative, the first-best and the 1997 emission policy cases.
} 
The discount factor is evaluated by the value of the real interest rate for the year 1999. The real interest rate is constructed by the difference of the average nominal interest rate and the weighted average inflation rate using real GDP data for the two countries.

In order to evaluate preference parameters related to these variables, we first assume for simplicity that $\alpha_{1}=1$ and $\beta_{1}=1$ for both countries. We then use the first-order conditions of our static program for obtaining useful information on the value of the quadratic terms in the utility function. Using the consumption data concerning the values of $A$ and $F$, we obtain $\alpha_{2}=0.0007 \beta_{2}$ for Romania and $\alpha_{2}=0.0009 \beta_{2}$ for Ukraine. We observe that Ukraine's population is more quickly saturated by the consumption of agricultural goods relative to fish goods than that of Romania.

The value of the agricultural productivity parameter $a$, which is expressed as $a=\frac{A}{N_{A}}$, is evaluated by using the agricultural value added and the agricultural employment data for each country. Similarly, the evaluation of the value of the fishery productivity $\bar{S} f$, which is expressed as $\bar{S} f=\frac{\bar{F}}{N_{F}}=\frac{F+L}{N_{F}}$, is obtained from the fishery value added, the fishery revenue loss and the fishery employment data. The lack of the fishery value added data for Ukraine leads us to assume for both countries the same ratio of agricultural productivity to fishery productivity as in Romania.

The evaluation of the fishery loss parameter, expressed as $\bar{S} \gamma=\frac{L}{P}$, is obtained from the data on the fishery resource loss for each country $L$ as well as on the total pollution stock $P$. This formulation allows for the fact that the countries have the same parameter $\gamma$ but different fishery loss, because they are characterized by different stationary fish stock levels $\bar{S}$ in their respective patches.

In this paper, we especially study the relation between the existing pollution stock and the loss of fishery resources at the north-western coast of the Black Sea. An implicit relationship exists, however, between algae production and the pollution stock, which has not been exploited in detail in our model. ${ }^{13}$ Because it is very

\footnotetext{
${ }^{13}$ In fact, the eutrophication phenomenon is caused, on the one hand, by phosphorus emissions and, on the other, by nitrogen emissions. It is known that it is generally difficult to determine the limiting nutrient (the one which limits algae production when it is available in smaller amounts) of algae production for large aquifers and coastal waters (Elofsson, (2003)). Concerning the Black Sea, the study of Cociasu, Petranu and Mihnea (1997) shows that large nitrogen/phosphorus ratios were registered during the 1990s suggesting that phosphorus is a limiting nutrient of the algae production in the Romanian shelf waters. However, the report of the International Study Group from the Black Sea Ecosystem Recovery Project (www.blacksea-environment.org/text/default.htm) refers to the
} 
difficult to construct the production function of algae at the north-western coast of the Black Sea, we have chosen to consider only the stock of total nitrogen for two reasons. On the one hand, personal calculations on the available concentration data show that in the 1970 s, 80 s and early 90 s the $\mathrm{N} / \mathrm{P}$ ratio was very low suggesting that nitrogen was the limiting nutrient. On the other hand, as Elofsson (2003) emphasizes, the natural purification rate of nitrogen is greater than that of phosphorus. Thus, the benefits of nitrogen reductions can be obtained sooner than those of phosphorus reductions in the long-term.

Concerning the data on emission levels, we use the pollution data on hot spots in each country. The pollution stock data include, for Ukraine, the average annual nutrient concentrations in the surface layer of the north-western shelf of the Black Sea and, for Romania, the mean annual concentrations of nutrients in the territorial waters at Constanta inshore station. We consider the 1979 level of the pollution stock as an initial stock. This stock has the characteristic of being moderate compared to other years' stock levels. Thus, we have $P_{0}=99000 \div 2=49500$. We divide by 2 because only half of the pollution stock comes from agricultural discharges (in Danube river basin countries, the agricultural sector is responsible for $50 \%$ of nutrient emissions).

The value of the inverse of the emission parameter $\mu$, expressed as $\mu=\frac{A}{E-c}$, and the value of the fixed emission component $c$, are evaluated by a crude simultaneous regression on the values of emissions $E$ and agricultural value added $A$, from 1996 to 1999. We estimate these parameters by introducing a constraint that the emission parameters are identical between the countries.

The natural purification rate of pollution $k$ (or self-purification rate), calculated from the formula $P_{2000}=(1-k)^{3} P_{1997}+(1-k)^{2} E_{1997}+(1-k) E_{1998}+E_{1999}$, is evaluated by using the data on total emissions (of both countries) and pollution stocks. Information on the empirical evaluation of the self-purification rate of pollution in seas or rivers is not easy to obtain. The difficulty is related to the change of these assimilation rates because of the seasons, degree of salinity, flow patterns etc. This problem is quite general; for example, Alaouze (1999) also acknowledges that current estimates of phosphorus assimilation rates in the Barwon and Darling rivers in New South Wales are not currently available (p.54).

Note that our resolution method naturally assumes the constancy of the natural purification rate of pollution between 1997 and 2000. This large value should be interpreted with caution. The nitrogen stock decreases for three reasons: evaporation,

speculation on whether nitrogen or phosphorus is the limiting nutrient between the north-western shelf and the Bosphorus gyre. 
diffusion in the sea and absorption by algae. In this paper, we focus on the latter mechanism because it is at the origin of the oxygen lack for fish (eutrophication). We assume that these three factors decrease the pollution stock by fixed proportions so that the total decay rate is $30 \%$. We also assume that the algae stock is proportional to the nitrogen stock.

The parameter values of the model are summarized in the table below:

Table I. The values of the parameters of the model

\begin{tabular}{|l|l|l|l|l|l|}
\hline Parameters & $a$ & $\bar{S} f$ & $\mu$ & $c$ & $\bar{S} \gamma$ \\
\hline Romania(indiced by 1) & 1747 & 24 & 3773584 & 8564 & 18 \\
\hline Ukraine(indiced by 2) & 1050 & 14 & 3773584 & 2991 & 341 \\
\hline
\end{tabular}

Table II. The values of the parameters of the model

\begin{tabular}{|l|l|l|l|l|l|}
\hline Parameters & $\alpha_{1}=\beta_{1}$ & - & $P_{0}$ ( for 1979) & $k$ & $r$ \\
\hline Romania & 1 & 3419000 & 49500 & 0.3 & 0.24 \\
\hline Ukraine & 1 & 4927000 & 49500 & 0.3 & 0.24 \\
\hline
\end{tabular}

We now present the simulation results. See the appendix for the description of the conditions on the convergence of value functions that simulations have to hold.

\section{$5 \quad$ Numerical Results}

We will run the simulations by changing parameter $\beta_{2}$, the only non-fixed parameter, to see the difference between total value functions in three different programs. Parameter $\beta_{2}$ will change in the same interval for the two countries. It is clear that the modification of parameter $\beta_{2}$ also means the modification of parameter $\alpha_{2}$ by the above relationship. We observe that the conditions on the convergence of value functions imposed on the model are validated for many values of $\beta_{2}$. For the simplicity of the presentation of simulation results, we will only consider the interval $\left[10^{-19}, 10^{3}\right]$.

\subsection{Sensitivity analysis of the results on the value of the $\beta_{2}$ parameter}

When parameter $\beta_{2}$ moves, for instance, from $10^{n}$ to $9 \times 10^{n}$ by $10^{n}$, we account for 81 cases. Applying the same type of operation for $n=-19$ to $n=3$, we can account for $81 \times 23=1863$ different cases. All these realized simulations obviously 
show us the superiority of the first-best outcome on the second-best outcomes in terms of total welfare. If we look at the comparison of the second-best options, we observe that the non-cooperative game dominates the uniform emission policy and the proposed 1997 policy in all cases. We also note that the uniform emission policy outperforms the proposed 1997 policy in 945 cases, with the corresponding interval for the values of $\beta_{2}$ being the interval $\left[10^{-19}, 10^{-8}\right]$. We have the opposite result in 918 cases, with the corresponding interval being $\left[10^{-8}, 10^{3}\right]$.

To have an idea of the magnitude of differences in the total welfare level between different institutional arrangements, we can look at the case where $\beta_{2}($ Romania $)=$ $10^{-8}$ and $\beta_{2}$ (Ukraine $)=10^{-8}$. In this case, the level of individual and total value functions with respect to four programs are:

Table III. The value functions in the noncooperative case and the uniform emission policy

\begin{tabular}{|c|c|c|}
\hline & VNC & VC \\
\hline Romania & $0.2332968105 \times 10^{12}$ & $0.2235102471 \times 10^{12}$ \\
\hline Ukraine & $0.1892704053 \times 10^{12}$ & $0.4399805078 \times 10^{20}$ \\
\hline Total & $0.4225673058 \times \mathbf{1 0}^{\mathbf{1 2}}$ & $0.4051887357 \times \mathbf{1 0}^{\mathbf{1 2}}$ \\
\hline
\end{tabular}

Table IV. The value functions in the first-best case and the proposed 1997 policy

\begin{tabular}{|c|c|c|}
\hline & VF & V1997 \\
\hline Romania & $0.2332956937 \times 10^{12}$ & $0.1978271637 \times 10^{11}$ \\
\hline Ukraine & $0.1892727398 \times 10^{12}$ & $0.2114258707 \times 10^{11}$ \\
\hline Total & $0.4225684336 \times \mathbf{1 0}^{\mathbf{1 2}}$ & $0.4092530345 \times \mathbf{1 0}^{\mathbf{1 1}}$ \\
\hline
\end{tabular}

where VNC, VC, VF and V1997 represent, respectively, the level of value functions in the non-cooperative, the uniform emission policy, the first-best and the proposed 1997 policy cases. We observe that Romania has a higher level of welfare than Ukraine in the non-cooperative and the first-best cases. We have the opposite result in the uniform emission policy and the proposed 1997 policy cases. If we consider the individual value functions of the countries, we can see that the ranking of Romania's welfare is: the non-cooperative, the first-best, the uniform emission policy and the proposed 1997 policy cases. Thus, Romania would lose by a movement from the non-cooperative case to the first-best case in terms of welfare. For Ukraine, we observe the following ranking of welfare: the uniform emission policy, the first-best, the non-cooperative and the proposed 1997 policy cases. Thus, Ukraine is advantaged by moving from the non-cooperative game to the first-best allocation. In that special case, Ukraine could make a side payment to Romania to move from the non-cooperative case to the first-best case. 
We can summarize, in the table below, the percentage deviation of the steadystate pollution stock levels compared to the highest pollution stock level in our data. This highest level corresponds to the pollution stock of the year 1998 and is equal to 224 925. The pollution stock level of 1997, being equal to 215350 , is included to evaluate the policy proposed for the Black Sea. The values of the percentage deviation of the steady-state pollution stock levels, when the parameter $\beta_{2}$ is equal to $10^{-8}$ for both countries, are as follows:

Table V. The percentage deviation of the steady-state pollution stock levels

\begin{tabular}{|l|l|l|l|}
\hline $\mathrm{pd}(\mathrm{Pnc})$ & $\mathrm{pd}(\mathrm{Pc})$ & $\mathrm{pd}(\mathrm{Pf})$ & $\mathrm{pd}(\mathrm{P} 1997)$ \\
\hline $\mathbf{2 . 9 8} \%$ & $\mathbf{4 . 7} \%$ & $\mathbf{3 . 0 8} \%$ & $\mathbf{4 . 2 6} \%$ \\
\hline
\end{tabular}

where Pnc, Pc, Pf and P1997 represent, respectively, the steady-state levels of the pollution stock in the non-cooperative, the uniform emission policy, the first-best allocation and the proposed 1997 policy cases. We first observe that the pollution stock levels in these respective cases are reduced by 3 to $5 \%$, compared to the highest stock level. But we notice that the pollution stock levels must be reduced by a lower percentage in the cases of uniform emission policy and the proposed 1997 policy, considering the steady-state pollution stock level in the first-best case. Naturally, the fact that the first-best pollution stock is inferior to the highest stock level indicates the necessity of reducing the pollution. This pollution stock reduction must be around $3 \%$, based on the predictions of our model. Finally, we note that the theoretical model largely reproduces the data, since the steady-state levels of the pollution stock in the non-cooperative $(\mathrm{Pnc}=218220)$, the uniform emission policy $(\mathrm{Pc}=214396)$ and the first-best $(\mathrm{Pf}=217990)$ cases are very close to the pollution stock of 1997.

Within the simulations realized when $\beta_{2}$ moves from $1 \times 10^{-8}$ to $9 \times 10^{-8}$ by $1 \times 10^{-8}$, i.e. in 81 cases, we make some observations. We first notice that the level of total emissions is highest in the non-cooperative game of countries. In the non-cooperative game, the non-coordinated and independent emission abatement efforts of countries lead to higher emissions. Additionally, we note that the level of total emissions is lowest in the 1997 policy option. Moreover, we notice that the emissions of Romania exceed the ones of Ukraine in the non-cooperative and firstbest allocations in a majority of cases. Finally, we observe that the welfare level in the non-cooperative game always exceeds the one in the first-best case for Romania. The opposite result holds for Ukraine. This means that Romania's losses are due to a movement from the non-cooperative case to the first-best case, whereas Ukraine benefits from such a movement. The fact that Ukraine suffers more significant 
damage from this global pollution makes it better off in the first-best case than in the initial non-cooperative case.

By simulation results, we notice that the precise value of the discount factor does not matter for the ranking of the different policies, but only for the levels of welfare and emissions. The higher the discount factor, the lower the total welfare. An increase in the value of the discount factor means that agents value current time more than future time. We also observe that the total level of emissions increases when the value of the discount factor increases. This is because when the discount factor is higher, agents are less patient and they prefer to consume more today and therefore to pollute more, sacrificing the consumption of fish in the future. The numerical applications also indicate that the precise value of the purification rate of pollution does not matter for the ranking of the different policies, but only for the levels of welfare and emissions. We note that the higher the assimilation rate, the higher the total welfare. An increase in the value of the assimilation rate means that the capacity of nature to absorb pollution is increased. When the purifying capacity of nature is significant, agents can consume more agricultural goods, ignoring the negative effects of this consumption and also consume more fish goods. We also notice that the total level of emissions increases when the value of the self-purification rate increases. This is because when the purification rate is higher, agents take advantage of this situation to increase their emissions.

Using the same values of the parameters, we run some simulations by taking into account the population size differences of the countries. We use the same interval for the values of $\beta_{2}\left[10^{-19}, 10^{-7}\right]$, which accounts for 1863 cases. The simulation results confirm the predictions of our model. On the one hand, the results show that the non-cooperative game dominates the other second-best policies, and the uniform emission policy dominates the 1997 policy in 918 cases, with the corresponding interval for the values of $\beta_{2}$ being the interval $\left[10^{-8}, 10^{-19}\right]$. On the other hand, we note that the non-cooperative game dominates the other second-best policies and the 1997 policy dominates the uniform emission policy in 945 cases, with the corresponding interval being $\left[10^{-8}, 10^{3}\right]$. These findings indicate that the population size differences between the countries does not alter the predictions of our model, especially the superiority result of the non-cooperative game on the other secondbest policies. Note that these new findings are not totally comparable with the other results because the objective functions are not the same. The introduction of the population size differences between the countries alters total welfare functions. 


\subsection{The Evolution of the Pollution Stock and Emissions}

Now, we describe the evolution of the pollution stock and total emission levels (for the two countries) for different institutional arrangements. Parameter $\beta_{2}$ is chosen as equal to $10^{-8}$ for both countries, in which case the non-cooperative game dominates the other second-best outcomes and the uniform emission policy outperforms the 1997 policy. The evolution of the pollution stock in the uniform policy case is illustrated in Figure 1. We notice that the pollution stock increases through time to converge to its steady-state value, at the same time that the emissions decrease in order to reach their stationary levels (see Figure 2 for the evolution of emissions in the uniform case).

The evolution of the pollution stock and emissions in the non-cooperative and first-best cases is illustrated in Figures 3 and 4 respectively. As expected, the stationary pollution stock level for the non-cooperative case is higher than that for the first-best case. It is worth noting that the scale in Figures 1 and 2 is smaller than the one in Figures 3 and 4.

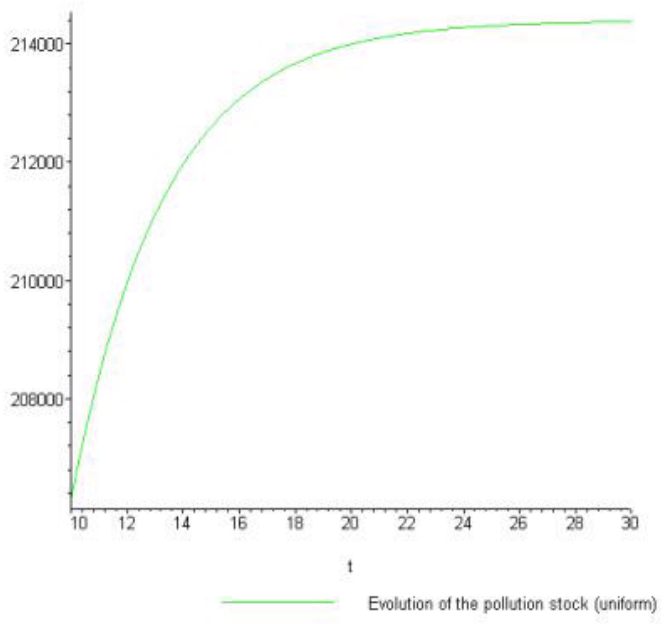

Figure 1. Evolution of the pollution stock in the uniform emission policy 


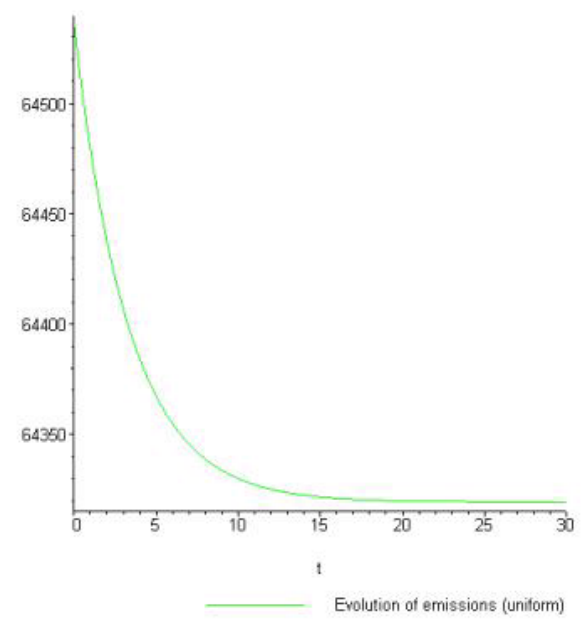

Figure 2. Evolution of emissions in the uniform emission policy 


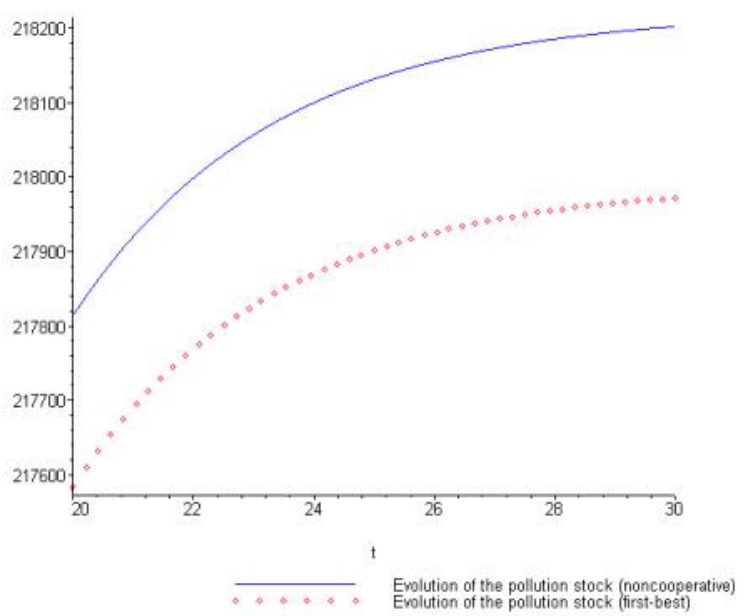

Figure 3. Evolution of the pollution stock in the noncooperative and first-best cases 


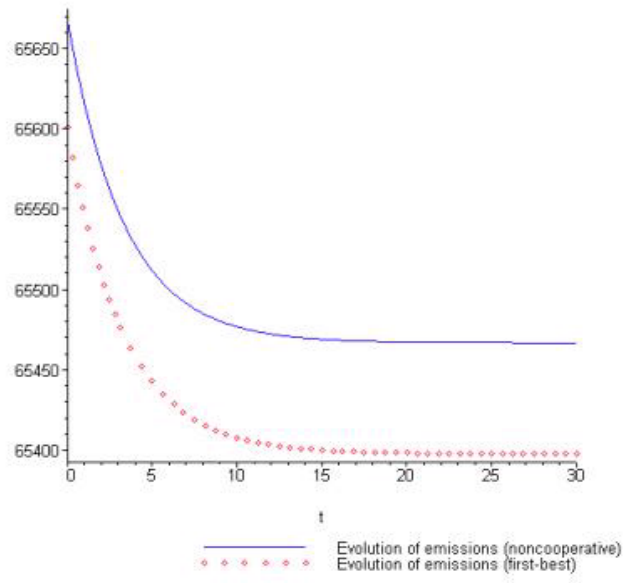

Figure 4. Evolution of emissions in the noncooperative and first-best cases

\subsection{Comments}

All the simulations made on the value of parameter $\beta_{2}$ show us that the noncooperative outcome widely dominates the uniform emission policy outcome in terms of total welfare. ${ }^{14}$ The intuition behind this result is the same as the one presented by List and Mason (2001). In the uniform emission policy, the regulator maximizes the total welfare of both countries by implementing a common emission rule across the countries. Thus, the regulator applies one shadow price for pollution. When the countries are very heterogeneous, these shadow prices are very different. As the utility functions of the two countries become different, the costs of the uniform emission policy exceed (existence of one shadow price) any benefits from supranational authority (elimination of free-riding). We might think that the decentralization of pollution control leads to total welfare level reductions because of

\footnotetext{
${ }^{14}$ This superiority result of a non-cooperative game over a uniform emission policy is reinforced if we consider, in addition, the monitoring and enforcement costs of a supranational authority when it implements uniform emission standards.
} 
the non-coordination problem in pollution abatement efforts. We observe, however, that the uniform emission policy is very constraining, since it does not take into account the different characteristics of countries (preferences, emission and damage functions). This result could be linked to the high degree of asymmetry between Romania and Ukraine, even though we had to make several assumptions, which introduce symmetry between these countries: the ratio of agricultural productivity on fishery productivity and some preference parameters $\left(\alpha_{1}, \beta_{1}\right)$ are assumed to be the same in both countries.

The superiority result of the non-cooperative game over the uniform emission policy is unchanged when we consider per capita emission standards. Considering part of the asymmetry between countries via population size differences does not help to increase the efficiency of the per capita uniform emission policy over the per capita non-cooperative game of the countries. It is important to note that the introduction of the population size differences between the countries alters total welfare functions, so that these new findings are not comparable with the other results.

Furthermore, all the simulations made on the value of parameter $\beta_{2}$ indicate that the non-cooperative outcome always dominates the new policy recommendation in terms of total welfare. This finding holds true when we take into account the population size differences between the countries. The policy proposed by the two Commissions is based on maintaining each country's 1997 emission level. This constraint leads to the superiority of the non-cooperative game over this specific policy. Moreover, we observe that the uniform emission policy outperforms the 1997 policy for the low levels of parameter $\beta_{2}$, with the corresponding interval being $\left[10^{-19}, 10^{-8}\right]$. This result is unchanged by the introduction of the population size differences across the countries. In the case of a uniform emission policy, there is a lower level of steady-state pollution stock than the pollution stock of 1997 . These findings could be explained by the fact that agents value more a low level of pollution stock in the uniform emission policy. Hence, agents would benefit more from the consumption of fish good when the parameter $\beta_{2}$ is low. We observe that the new policy recommendation is partly dominated by the other two second-best options, in terms of the total welfare. Moreover, we notice that the 1997 policy seems to be very restrictive in terms of nitrogen pollution stock reductions, compared to the steady-state pollution stock in the first-best case. We have to note that the 1997 policy has a multi-pollutant characteristic. It aims to reduce the levels of nitrogen and phosphorus emissions as well as other hazardous substances exceeding those levels observed in 1997. Our welfare results, however, are based only on the effects 
of nitrogen emissions in the Black Sea.

We have to note that these findings are obtained using the available data on the environmental status of the Black Sea, which have some shortcomings. First, the lack of time-series data for fishery value added and agricultural value added does not allow the estimation of the preference parameters in the utility function. In the case of Ukraine, the lack of the fishery value added data leads us to assume the same ratio of agricultural productivity to fishery productivity as in Romania. The same problem of the absence of data for different points in time concerning the agricultural value added and the emission levels limits the quality of the adjustment of the regression model on the parameters of the emission function.

\section{Conclusion}

In the case of the Black Sea, the most important transboundary pollution problem has been identified as eutrophication, which is caused by the discharge of nitrogen and phosphorus compounds into the water. This paper uses a dynamic game model for Romania and Ukraine, which are coastal states along the Black Sea, to study the welfare consequences of institutional arrangements for transboundary pollution control. We study one of the aspects of the pollution problem in the Black Sea, which is the most severe, the nitrogen emissions related to agricultural polluting activities.

Our findings first indicate that the highest level of the pollution stock observed at the north-western part of the Black Sea, corresponding to the pollution stock of the year 1998, is inefficient. We show that the optimal stationary level of the pollution stock is almost $95 \%$ of this level. Furthermore, our results indicate that the 1997 policy seems to be very restrictive, when it is applied to agricultural nitrogen emissions. Another policy is also evaluated: a uniform emission policy. Our findings indicate that this policy seems to be extremely restrictive compared to the steadystate pollution stock in the first-best case.

Concerning the evaluation of the 1997 policy proposed for the Black Sea pollution problem, it is important to note that our evaluation is partial because we only focus on the nitrogen emissions of the agricultural sector. An overall evaluation of this policy must be applied to all the sectors at the origin of the eutrophication phenomenon and to several pollutants such as nitrogen, phosphorus and other hazardous substances. Finally, we show that the contribution of agricultural activities to the observed pollution level is very high, but not sufficiently high, since the op- 
timal stationary level of the pollution stock is almost $95 \%$ of the highest pollution stock in our data. Hence, discharges coming from different sources, other than the agricultural sector, such as the domestic and industrial sectors, could be reduced.

Further more, our welfare analysis indicates that the 1997 policy and the uniform emission policy are dominated by the laisser-faire solution, which indicates the importance of the agricultural sector for these coastal countries. However, it is possible to consider other policies which would be better than the laisser-faire solution in terms of total welfare. For instance, better cooperation across countries could allow them to be closer to the first-best solution (full cooperation).

This model presents some limits. First, we take into account only one of the factors causing the deterioration of fishery resources in the Black Sea, which is nutritive pollution. Other factors in the origin of the ecosystem deterioration, such as the introduction of exotic species or the over-exploitation of fishery resources, have not been considered. Secondly, we have only studied damage caused to fishery resources by pollution. We have not considered other types of damage that have occurred on the north-western coast of the Black Sea affecting biological diversity and human use of the sea, including tourism and recreation. Finally, the data on the environmental status of the Black Sea could be richer. We hope that a more complete set of data will be available as soon as possible for future research.

\section{References}

Alaouze, C.M. (1999): An Economic Analysis of the Eutrophication Problem of the Barwon and Darling rivers in the New South Wales, Australian Economic Papers, vol.38, issue 1.

Barrett, S. (1994): Self-Enforcing International Environmental Agreements, Oxford Economic Papers, vol.46.

Basar, T., Oldser, G.J. (1982): Dynamic non-cooperative Game Theory, Academic Press, vol.160.

Black Sea Environmental Programme (BSEP), (2002): The State of the Environment of the Black Sea: Pressures and Trends 1996-2000.

Black Sea Environmental Priorities Study, (1998): National Report of Ukraine, Black Sea Studies, U.N. Publications, New York.

Carraro, C., Siniscalco, D. (1993): Strategies for the International Protection of the Environment, Journal of Public Economics, vol.52.

Chander, P., Tulkens, H. (1995): A Core-theoretic Solution for the Design of Cooperative Agreements on Transfrontier Pollution, International Tax and Public Finance 2, 279-293. 
Cociasu, A.,Petranu, A., Mihnea, P.E. (1997): Ecological Indicators of the Romanian Coastal Waters, Black Sea Pollution Assessment, U.N. Publications, New York.

Commission of the European Communities, (2001): Environmental Cooperation in the Danube-Black Sea Region, Communication from the Commission.

Commission of the Protection of the Black Sea Against Pollution, (2001): Implementation of the Strategic Action Plan for the Rehabilitation and Protection of the Black Sea, 1996-2001.

Danube Pollution Reduction Programme, (1998): National Reviews: Romania, Technical Report.

Danube Pollution Reduction Programme, (1998): National Reviews: Ukraine, Project Files.

Danube Pollution Reduction Programme, (1999): Causes and Effects of Eutrophication in the Black Sea, Summary Report.

Elofsson, K., Policies for Interactive Water Pollutants, Paper Prepared for 2003 Annual Conference of European Association of Environmental and Resource Economics (EAERE).

Feenstra, T., Kort, P.M., de Zeeuw, A. (2001): Environmental Policy Instruments in an International Duopoly with Feedback Investment Strategies, Journal of Economic Dynamics and Control, vol.25.

Fernandez, L. (2002): Trade's Dynamic Solutions to Transboundary Pollution, Journal of Environmental Economics and Management, vol.43.

Fudenberg, D., Tirole, J. (1991): Game Theory, The MIT Press.

Gren, I.M., (2001): International versus National Actions Against Nitrogen Pollution of the Baltic Sea, Environmental and Resource Economics, vol.20.

Gren, I.M, Folmer, H. (2002): Cooperation versus Noncooperation in Cleaning of an International Water Body with Stochastic Damage: the Case of the Baltic Sea, Paper Prepared for the 2002 World Congress of Environmental and Resource Economists.

Hoel, M. (1991): Global Environmental Problems: the Effects of Unilateral Actions by One Country, Journal of Environmental Economics and Management, vol.20.

IMF External Publications, (2003): Romania: Selected Issues and Statistical Appendix, Series Country Report 03/12.

IMF External Publications, (2001): Ukraine: Statistical Appendix, Country Report 01/28.

Karp, L. (1992): Social Welfare in a Common Property Oligopoly, International 
Economic Review, vol.33, no.2.

Knowler, D., Barbier, E.B., Strand, I. (1997): The Effects of Pollution on Open Access Fisheries: a Case Study of the Black Sea, Paper Prepared for 8th Annual Conference of European Association of Environmental and Resource Economics.

List, J.A., Mason, C.F. (2001): Optimal Institutional Arrangements for Transboundary Pollutants in a Second-Best World: Evidence from a Differential Game with Asymmetric Players, Journal of Environmental Economics and Management, vol.42.

Maler, K-G., de Zeeuw, A. (1998): The Acid Rain Differential Game, Environmental and Resource Economics, vol.12.

Mason, C.F., Polasky, S. (1997): The Optimal Number of Firms in the Commons: a Dynamic Approach, Canadian Journal of Economics, vol.30, no.46.

Mason, C.F., Polasky, S. (2002): Strategic Preemption in a Common Property Resource: a Continuous Time Approach, Environmental and Resource Economics, vol.23.

Mee, D. Laurence (2002), How to Save the Black Sea, Your Guide to the Black Sea Strategic Action Plan.

Missfeldt, F. (1999): Game Theoretic Modelling of Transboundary Pollution, Journal of Economic Surveys, vol.13, no.3.

Sanchirico, J.N., Wilen, J.E. (1999): Bioeconomics of Spatial Exploitation in a Patchy Environment, Journal of Environmental Economics and Management, vol.37.

Saving the Black Sea, (2002): Official Newsletter of the Black Sea Environmental Programme, Issue 7.

Sekulic, B., Vertacnik, A. (1997): Comparison of Anthropoligical and Natural Input of Substances through Waters into Adriatic, Baltic and Black Sea, Water Resources, vol.31, no.12.

Zaitsev, Yu.P., Alexandrov, B.G., Berlinsky, N.A. (2002): Europe's Biodiversity, Seas Around Europe, the Black Sea, European Environment Agency.

Web Pages:

Black Sea Transboundary Diagnotic Analysis, (1996):

www.grid.unep.ch/bsein/tda.main.htm

Black Sea Environmental Programme (BSEP):

www.blacksea-environment.org

International Commission for the Protection of the Danube River:

www.icpdr.org 


\section{Appendix 1: Resolution of the Non-cooperative Game}

The equality of the two values of $\lambda_{i}$ gives us:

$$
\begin{gathered}
f_{i} E_{i}-d_{i} P-a_{i}=\delta_{i} P+\varepsilon_{i} \\
\Longleftrightarrow E_{i}=\frac{a_{i}+\varepsilon_{i}+\left(\delta_{i}+d_{i}\right) P}{f_{i}}
\end{gathered}
$$

are the emissions of country $i$.

Similarly, the emissions of country $j$ are denoted:

$$
E_{j}=\frac{a_{j}+\varepsilon_{j}+\left(\delta_{j}+d_{j}\right) P}{f_{j}}
$$

The derivative of these emissions of the country $j$ with respect to the pollution stock is:

$$
\frac{d E_{j}}{d P}=\frac{\delta_{j}+d_{j}}{f_{j}}
$$

The derivative of the expression $\lambda_{i}=\delta_{i} P+\varepsilon_{i}$ with respect to time gives us:

$$
\begin{gathered}
\dot{\lambda}_{i}=\delta_{i} \dot{P} \\
\Longleftrightarrow \dot{\lambda}_{i}=\delta_{i}\left(E_{i}+E_{j}-k P\right)
\end{gathered}
$$

If we replace the obtained values of the emissions of both countries $E_{i}$ and $E_{j}$, we obtain:

$$
\begin{gathered}
\dot{\lambda}_{i}=\delta_{i}\left(\frac{a_{i}+\varepsilon_{i}+\left(\delta_{i}+d_{i}\right) P}{f_{i}}+\frac{a_{j}+\varepsilon_{j}+\left(\delta_{j}+d_{j}\right) P}{f_{j}}-k P\right) \\
\Longleftrightarrow \dot{\lambda}_{i}=\delta_{i}\left(\frac{a_{i}+\varepsilon_{i}}{f_{i}}\right)+\delta_{i}\left(\frac{a_{j}+\varepsilon_{j}}{f_{j}}\right)+P\left[\frac{\delta_{i}\left(\delta_{i}+d_{i}\right)}{f_{i}}+\frac{\delta_{i}\left(\delta_{j}+d_{j}\right)}{f_{j}}-\delta_{i} k\right]
\end{gathered}
$$

The second of the first-order conditions can be rewritten as:

$$
\begin{aligned}
\dot{\lambda}_{i}= & r\left(\delta_{i} P+\varepsilon_{i}\right)+b_{i} P+c_{i}-d_{i}\left(\frac{a_{i}+\varepsilon_{i}+\left(\delta_{i}+d_{i}\right) P}{f_{i}}\right)+ \\
& \left(\delta_{i} P+\varepsilon_{i}\right) k-\left(\delta_{i} P+\varepsilon_{i}\right)\left(\frac{\delta_{j}+d_{j}}{f_{j}}\right)
\end{aligned}
$$




$$
\begin{aligned}
\Longleftrightarrow & \dot{\lambda}_{i}=r \varepsilon_{i}+c_{i}-d_{i}\left(\frac{a_{i}+\varepsilon_{i}}{f_{i}}\right)+\varepsilon_{i} k-\varepsilon_{i}\left(\frac{\delta_{j}+d_{j}}{f_{j}}\right)+ \\
& P\left[r \delta_{i}+b_{i}-\frac{d_{i}\left(\delta_{i}+d_{i}\right)}{f_{i}}+\delta_{i} k-\delta_{i}\left(\frac{\delta_{j}+d_{j}}{f_{j}}\right)\right]
\end{aligned}
$$

Equations (1) and (2) are both functions of the pollution stock $P$ and define a system of four equations with four unknown parameters $\left(\varepsilon_{i}, \varepsilon_{j}, \delta_{i}, \delta_{j}\right)$.

$$
\begin{gathered}
\delta_{i}\left(\frac{a_{i}+\varepsilon_{i}}{f_{i}}\right)+\delta_{i}\left(\frac{a_{j}+\varepsilon_{j}}{f_{j}}\right)=r \varepsilon_{i}+c_{i}-d_{i}\left(\frac{a_{i}+\varepsilon_{i}}{f_{i}}\right)+\varepsilon_{i} k-\varepsilon_{i}\left(\frac{\delta_{j}+d_{j}}{f_{j}}\right) \\
\delta_{j}\left(\frac{a_{j}+\varepsilon_{j}}{f_{j}}\right)+\delta_{j}\left(\frac{a i+\varepsilon i}{f_{i}}\right)=r \varepsilon_{j}+c_{j}-d_{j}\left(\frac{a_{j}+\varepsilon_{j}}{f_{j}}\right)+\varepsilon_{j} k-\varepsilon_{j}\left(\frac{\delta_{i}+d_{i}}{f_{i}}\right) \\
\frac{\delta_{i}\left(\delta_{i}+d_{i}\right)}{f_{i}}+\frac{\delta_{i}\left(\delta_{j}+d_{j}\right)}{f_{j}}-\delta_{i} k=r \delta_{i}+b_{i}-\frac{d_{i}\left(\delta_{i}+d_{i}\right)}{f_{i}}+\delta_{i} k-\frac{\delta_{i}\left(\delta_{j}+d_{j}\right)}{f_{j}} \\
\frac{\delta_{j}\left(\delta_{j}+d_{j}\right)}{f_{j}}+\frac{\delta_{j}(\delta i+d i)}{f_{i}}-\delta_{j} k=r \delta_{j}+b j-\frac{d_{j}\left(\delta_{j}+d_{j}\right)}{f_{j}}+\delta_{j} k-\frac{\delta_{j}\left(\delta_{i}+d_{i}\right)}{f_{i}}
\end{gathered}
$$

By solving this system, it is possible to calculate the value function as a function of the fundamental parameters. Indeed, the value function of country $i$ in the noncooperative case is the following:

$$
\begin{gathered}
V_{i}=\int_{0}^{\infty} e^{-r t} U_{i} d t \\
\Longleftrightarrow V_{i}=\int_{0}^{\infty} e^{-r t}\left[\begin{array}{c}
e_{i}+a_{i}\left(\frac{a_{i}+\varepsilon_{i}+\left(\delta_{i}+d_{i}\right) P}{f_{i}}\right)-\frac{f_{i}}{2}\left(\frac{a_{i}+\varepsilon_{i}+\left(\delta_{i}+d_{i}\right) P}{f_{i}}\right)^{2}- \\
\frac{b_{i}}{2} P^{2}-c_{i} P+d_{i} P\left(\frac{a_{i}+\varepsilon_{i}+\left(\delta_{i}+d_{i}\right) P}{f_{i}}\right)
\end{array}\right] d t
\end{gathered}
$$

The equation which explains the evolution of the pollution stock has the following form: 


$$
\begin{gathered}
\dot{P}=\left(\frac{a_{i}+\varepsilon_{i}+\left(\delta_{i}+d_{i}\right) P}{f_{i}}\right)+\left(\frac{a_{j}+\varepsilon_{j}+\left(\delta_{j}+d_{j}\right) P}{f_{j}}\right)-k P \\
\Longleftrightarrow \dot{P}=\left(\frac{a_{i}+\varepsilon_{i}}{f i}\right)+\left(\frac{a_{j}+\varepsilon_{j}}{f_{j}}\right)+P\left(\left(\frac{\delta_{i}+d_{i}}{f_{i}}\right)+\left(\frac{\delta_{j}+d_{j}}{f_{j}}\right)-k\right)
\end{gathered}
$$

The integral of this differential equation gives us the expression of the pollution stock $P_{t}$ :

$$
P_{t}=\frac{-\left(\frac{a_{i}+\varepsilon_{i}}{f_{i}}+\frac{a_{j}+\varepsilon_{j}}{f_{j}}\right)}{\left(\frac{\delta_{i}+d_{i}}{f_{i}}+\frac{\delta_{j}+d_{j}}{f_{j}}-k\right)}+e^{\left[\frac{\delta_{i}+d_{i}}{f_{i}}+\frac{\delta_{j}+d_{j}}{f_{j}}-k\right] t}\left(P_{0}+\frac{\left(\frac{a_{i}+\varepsilon_{i}}{f_{i}}+\frac{a_{j}+\varepsilon_{j}}{f_{j}}\right)}{\left(\frac{\delta_{i}+d_{i}}{f_{i}}+\frac{\delta_{j}+d_{j}}{f_{j}}-k\right)}\right)
$$

where $P_{0}$ is the initial pollution stock at date 0 .

To obtain the expression of the value function of the country $i$, we replace the expression of the pollution stock $P_{t}$ in the value function. We obtain a relation, which can be reduced to the following expression:

$$
V_{i}=\int_{0}^{\infty} e^{-r t}\left[z_{1}+z_{2} e^{w t}+z_{3} e^{2 w t}\right] d t
$$

where $w=\frac{\delta_{i}+d_{i}}{f_{i}}+\frac{\delta_{j}+d_{j}}{f_{j}}-k$ ( $k$ being the natural purification rate of pollution) and $z_{1}, z_{2}, z_{3}$ are constant parameters depending on the fundamental parameters.

The integral of the value function gives us:

$$
V_{i}=-\frac{1}{r}\left[z_{1} e^{-r t}\right]_{0}^{\infty}+\frac{1}{-r+w}\left[z_{2} e^{(-r+w) t}\right]_{0}^{\infty}+\frac{1}{-r+2 w}\left[z_{3} e^{(-r+2 w) t}\right]_{0}^{\infty}
$$

hence (assuming that $-r+w<0$ and $-r+2 w<0$ )

$$
V_{i}=\frac{1}{r} z_{1}^{i}+\frac{1}{r-w} z_{2}^{i}+\frac{1}{r-2 w} z_{3}^{i}
$$

is country $i$ 's value function.

$$
V_{j}=\frac{1}{r} z_{1}^{j}+\frac{1}{r-w} z_{2}^{j}+\frac{1}{r-2 w} z_{3}^{j}
$$

is the value function of country $j$.

Thus, the sum of the value functions in the non-cooperative case is: 


$$
V_{N C}=V_{i}+V_{j}=\frac{1}{r}\left(z_{1}^{i}+z_{1}^{j}\right)+\frac{1}{r-w}\left(z_{2}^{i}+z_{2}^{j}\right)+\frac{1}{r-2 w}\left(z_{3}^{i}+z_{3}^{j}\right)
$$

\section{Appendix 2: Per Capita Emission Regimes}

See below the programs in the first-best and the 1997 policy cases.

Non-cooperative game

Here, the only change is the total welfare function, which becomes:

$$
V_{N C}=V_{i}+T V_{j}=\frac{1}{r}\left(z_{1}^{i}+T z_{1}^{j}\right)+\frac{1}{r-w}\left(z_{2}^{i}+T z_{2}^{j}\right)+\frac{1}{r-2 w}\left(z_{3}^{i}+T z_{3}^{j}\right)
$$

First-best allocation

$$
\begin{aligned}
& \max _{E_{1}, E_{2}} \int\left[U_{1}\left(E_{1}, P\right)+T U_{2}\left(E_{2}, P\right)\right] e^{-r t} d t \\
\dot{P}= & E_{1}+E_{2}-k P
\end{aligned}
$$

1997 policy

$$
\int\left[U_{1}\left(E_{1}, P\right)+T U_{2}\left(E_{2}, P\right)\right] e^{-r t} d t
$$

where $E_{1}=E_{1}^{1997}$ and $E_{2}=E_{2}^{1997}$.

\section{Appendix 3: Checking for the Conditions} Optimality Conditions

The original utility function that incorporates a term on $E \times P$ is the following:

$$
U_{i}=e_{i}+a_{i} E_{i}-\frac{f_{i}}{2} E_{i}^{2}-c_{i} P-\frac{b_{i}}{2} P^{2}+d_{i} E_{i} P
$$

Another utility function without a crossed term on the choice and stock variables is the following:

$$
U=g_{1}+g_{2} B+g_{3} P+g_{4} B^{2}+g_{5} P^{2}
$$

where $B$ is the choice variable and $P$ is the state variable.

The corresponding values of the new variable and parameters are as follows: 


$$
\begin{aligned}
& B=\mu(E-c)+P \frac{\bar{S}^{2} f \gamma}{-^{2}} \\
& a\left(\frac{\bar{S} f^{2}}{a^{2}}+\frac{\alpha_{2}}{\beta_{2}}\right) \\
& g_{1}=\beta_{1} \bar{N} \bar{S} f-\frac{1}{2} \beta_{2} \bar{N}^{2} \bar{S}^{2} f^{2} \\
& g_{2}=\alpha_{1}-\frac{\beta_{1} \bar{S} f+\beta_{2} \bar{S}^{2} f^{2} \bar{N}}{a} \\
& g_{3}=\frac{\alpha_{1} \bar{S}^{2} f \gamma}{a\left(\frac{\bar{S}^{2} f^{2}}{a^{2}}+\frac{\alpha_{2}}{\beta_{2}}\right)}+\frac{\beta_{1} \bar{S}^{3} f^{2} \gamma}{a^{2}\left(\frac{\bar{S}^{2} f^{2}}{a^{2}}+\frac{\alpha_{2}}{\beta_{2}}\right)}-\beta_{1} \bar{S} \gamma \\
& -\frac{\beta_{2} \bar{S}^{4} f^{3} \bar{N} \gamma}{-^{2}}+\beta_{2} \bar{S}^{2} \gamma \bar{N} f \\
& a^{2}\left(\frac{\bar{S} f^{2}}{a^{2}}+\frac{\alpha_{2}}{\beta_{2}}\right) \\
& g_{4}=-\frac{1}{2} \beta_{2}\left(\frac{\bar{S}^{2} f^{2}}{a^{2}}+\frac{\alpha_{2}}{\beta_{2}}\right) \\
& g_{5}=\frac{1}{2} \frac{\beta_{2} \bar{S}^{4} f^{2} \gamma^{2}}{a^{2}\left(\frac{\bar{S}^{2} f^{2}}{a^{2}}+\frac{\alpha_{2}}{\beta_{2}}\right)}-\frac{1}{2} \beta_{2} \bar{S}^{2} \gamma^{2}
\end{aligned}
$$

We solve the differential game for each utility function. We take the time derivative of the first one of the first-order conditions and equalize it to the second firstorder conditions for each utility function. We obtain an equation for each case. We show that these two equations are equivalent. This indicates that the introduction of a crossed term on the choice and state variables does not change the nature of the linear-quadratic differential game. The only change is the resulting optimality conditions. The new optimality conditions are that $g_{4}<0$ and $g_{5}<0$, which require that the parameters $\alpha_{2}$ and $\beta_{2}$ are positive (Basar and Oldser, 1982).

Convergence Conditions

We have:

$$
V_{N C}=\frac{1}{r}\left(z_{1}^{i}+z_{1}^{j}\right)+\frac{1}{r-w}\left(z_{2}^{i}+z_{2}^{j}\right)+\frac{1}{r-2 w}\left(z_{3}^{i}+z_{3}^{j}\right)
$$


The conditions that must be respected are the following:

$$
\begin{aligned}
(-r+w) & <0 \Longleftrightarrow w<r \\
(-r+2 w) & <0 \Longleftrightarrow w<\frac{r}{2}
\end{aligned}
$$

The equation of the pollution stock is described by:

$$
P=-h+\exp (w \times t) \times\left(P_{0}+h\right)
$$

The conditions that must be respected are the following:

$$
\begin{gathered}
w<0 \\
-h>0
\end{gathered}
$$

The above conditions must hold because the pollution stock must converge to its non-negative stationary value $(-h)$ at infinity.

If $w<0$, then necessarily $w<\frac{r}{2}$ is true.

\section{Appendix 4: Evaluation of Preference Parameters}

Here, we try to evaluate a relation between the quadratic terms in the utility function using the first-order conditions of our static model:

$$
\begin{aligned}
& \max \int\left[\alpha_{1} A-\frac{\alpha_{2}}{2} A^{2}+\beta_{1} F-\frac{\beta_{2}}{2} F^{2}\right] e^{-r t} d t \\
A= & \mu(E-c) \\
\bar{F}= & \bar{S} f N_{F} \\
F= & \bar{F}-\bar{S} \gamma P \\
A= & a N_{A}
\end{aligned}
$$

where the last three conditions give the following condition:

$$
\bar{N}=N_{A}+N_{F}=\frac{A}{a}+\frac{F+\bar{S} \gamma P}{\bar{S} f}
$$


The Lagrangian related to this problem is the following:

$$
L=U(A, F)+\lambda_{1}\left(\bar{N}-\frac{A}{a}-\frac{(F+\bar{S} \gamma P)}{\bar{S} f}\right)+\lambda_{2}(A-\mu(E-c))
$$

The first-order conditions of the static program are the following:

$$
\begin{aligned}
\frac{\partial U}{\partial A}-\frac{\lambda_{1}}{a}+\lambda_{2} & =0 \\
\frac{\partial U}{\partial F}-\frac{\lambda_{1}}{\bar{S} f} & =0
\end{aligned}
$$

By replacing the expression of the shadow variable $\frac{\partial U}{\partial F} \bar{S} f$ in the first condition, we obtain: $\frac{\partial U}{\partial A}-\frac{\frac{\partial U}{\partial F} \bar{S} f}{a}+\lambda_{2}=0$. We assume that the shadow variable $\lambda_{2}$ associated with the evolution of emissions $\left(E=\frac{1}{\mu} A+c\right)$ is almost constant during the 1990s, since the pollution stock stayed relatively constant during this period (Cociasu et al., (1997)). Assuming that $\alpha_{1}=1$ and $\beta_{1}=1$ for both countries, we obtain the following static arbitrage condition for a given country between fish and agricultural goods, considered between two dates $t$ and $t-1: \alpha_{2}\left(A_{t}-A_{t-1}\right)-\frac{\bar{S} f}{a} \beta_{2}\left(F_{t}-F_{t-1}\right)=0$.

The data concerning the values of the agricultural consumption (cereal products) $A$ and the fish consumption $F$ in terms of kilos per capita for Romania and Ukraine are:

Table VI. Agricultural consumption $A$ and fish consumption $F$ for Ukraine

\begin{tabular}{|l|l|l|}
\hline Ukraine & $A$ (kg,per capita) & $F$ (kg, per capita) \\
\hline 1994 & 134.8 & 3.5 \\
\hline 1995 & 128.4 & 3.6 \\
\hline 1996 & 124 & 4.3 \\
\hline 1997 & 134 & 5 \\
\hline 1998 & 126 & 5.9 \\
\hline 1999 & 122 & 7.2 \\
\hline
\end{tabular}


Table VII. Agricultural consumption $A$ and fish consumption $F$ for Romania

\begin{tabular}{|l|l|l|}
\hline Romania & $A(\mathrm{~kg}$, per capita) & $F(\mathrm{~kg}$, per capita) \\
\hline 1994 & 158.6 & 2.6 \\
\hline 1995 & 162.4 & 2.8 \\
\hline 1996 & 160.6 & 2.9 \\
\hline 1997 & 169.8 & 2 \\
\hline 1998 & 166.7 & 3 \\
\hline 1999 & 166.3 & 2.2 \\
\hline
\end{tabular}

Source: Datastream Data Base $(A)$.

Using this information, the arbitrage condition for each country becomes:

$$
\begin{array}{cl}
\text { Romania } & : \alpha_{2}(3.8)-\frac{24}{1747} \beta_{2}(0.2)=0 \Longleftrightarrow \alpha_{2}=0.0007 \beta_{2} \\
\text { Ukraine } & : \alpha_{2}(10)-\frac{14}{1050} \beta_{2}(0.7)=0 \Longleftrightarrow \alpha_{2}=0.0009 \beta_{2}
\end{array}
$$

Here, we try to evaluate a common discount factor for both countries. The value of a real interest rate will play the role of the discount factor. The difference between the average nominal interest rate $(58.1 \%)$ and the weighted average inflation rate using real GDP data $(33.6 \%$ ) gives us an approximation of the average real interest rate, which is equal to $24 \%$ for the year 1999 .

The interest rate, inflation rate and GDP values for both countries are:

Table VIII. Interest rate, Inflation rate and GDP

\begin{tabular}{|l|l|l|}
\hline & Romania & Ukraine \\
\hline Lending rates (for 1999) & 61.2 & 55 \\
\hline CPI inflation rate (for 1999) & 54.8 & 19.2 \\
\hline GDP (1999, billions \$) & 28.5 & 41.8 \\
\hline
\end{tabular}

Source: Datastream Database (lending rates) and IMF External Publications Statistical Appendix (Ukraine 2001, Romania 2003)(CPI inflation rate), World Bank Development Indicators (GDP, in constant prices of 1995).

We first calculate the average of nominal interest rates:

$$
r_{n}=\frac{61.2+55}{2}=58.1
$$

Later, we calculate the weighted average of the inflation rate using real GDP data: 


$$
\pi=\frac{19.2 \times 41800000000+54.8 \times 28500000000}{41800000000+28500000000}=\frac{8025.6+15618}{703}=33.6
$$

\section{Appendix 5: Evaluation of Production Parameters}

Here, we try to evaluate the agricultural and fishery productivity as well as the fishery loss parameter.

The value of the agricultural productivity parameter $a$ is obtained from the following relationship:

$$
a=\frac{A}{N_{A}}
$$

where $A$ and $N_{A}$ represent, respectively, the agricultural value added and the employment in the agricultural sector of a specific country.

The data on the agricultural value added $A$ are extracted from the World Bank Development Indicators. The values are for the year 1999 and are expressed in US\$ in terms of 1995 prices: $A$ (Romania)=5 770000000 and $A$ (Ukraine)=5 130000 000. Using the agricultural employment data for 1999, we find the following values for the agricultural productivity:

$$
\begin{aligned}
& \text { Romania: } a=\frac{A}{N_{A}}=\frac{5770000000}{3302000}=1747 \\
& \text { Ukraine: } a=\frac{A}{N_{A}}=\frac{5130000000}{4851000}=1050
\end{aligned}
$$

These estimated parameter values mean that to obtain almost the same agricultural value added, we would need more workers in Ukraine than in Romania.

Similarly, the value of the fishery productivity $\bar{S} f$ is obtained from the following relationship:

$$
\bar{S} f=\frac{\bar{F}}{N_{F}}=\frac{F+L}{N_{F}}
$$

where $F, L$ and $N_{F}$ represent, respectively, the fishery value added, the fishery revenue loss and the employment in the fishery sector of a specific country. We use the data on the fishery value added concerning the variable $F$ for Romania. The data on the fishery revenue loss $L$ are also available for each country. 
We have the data on the fishery value added $F$ for Romania in billion lei on current prices, which is equal to 19 billion lei for 1998 (the latest date available is the year 1998, Source: Annual Statistics for Romania, 2001). To convert this value to US $\$$, we use the exchange rate, lei per US $\$$, which is equal to $1 U S \$=10951$ lei, for 1998 (Source: IMF Selected Issues and Statistical Appendix, Country Report No. 03/12, January 2003). So, we obtain $F$ (Romania, 1998,US\$)=1 734 985. To convert this value to 1995 US $\$$ prices, we divide the number by $(1+$ the total inflation rate in United States between 1995 and 1998), i.e. 1.067. The inflation rates under consideration for the United States are the following: $1995-1996$ : 2.9; $1996-1997$ : 2.3; 1997-1998 : 1.5 (source: OECD consumer price indices, percentage change from previous years, 2003, data on wages, costs, unemployment and inflation).

We use the findings of a study ${ }^{15}$ on fishery resources losses from 1970 to 1990 in Romania and Ukraine. This study indicates an estimation of these losses as $\$ 4$ million per year for Romania and $\$ 75$ million per year for Ukraine. The Black Sea Environmental Priorities Study (1998) for Ukraine reports that by expert estimation, marine pollution may have been responsible for approximately 50-60\% of the decline in fish productivity (p.38). Consequently, we first consider the $50 \%$ of total fish losses which is caused by marine pollution. Because we are interested in the negative relationship between agricultural emissions and fishery revenue losses, we then account for the $50 \%$ of losses induced by marine pollution (in the Danube river basin countries, the agricultural sector is responsible for $50 \%$ of nutrient emissions).

The fishery loss data $(L)$ are expressed in terms of 1990 US $\$$. The estimations of these losses are $\$ 4$ million per year for Romania and $\$ 75$ million per year for Ukraine. In order to convert these values to 1995 US $\$$ prices, we multiply the numbers by (1+the total inflation rate in United States between 1990 and 1995), i.e. 1.156. The inflation rates under consideration for the United States are the following: $1990-1991: 4.2 ; 1991-1992: 3.0 ; 1992-1993$ : $3.0 ; 1993$ - 1994 : 2.6; 1994 - 1995 : 2.8 (source: OECD consumer price indices, percentage change from previous years, 2003). We also apply the transformations to fishery losses explained in the text. Using the data described above and the fishery employment data, we can obtain the evaluation of the fishery productivity $\bar{S} f$ for Romania:

$$
\bar{S} f(\text { Romania })=\frac{F+L}{N_{F}}=\frac{1626040+1156000}{117000}=24
$$

The information on the fishery value added data in Ukraine is not available. To

\footnotetext{
${ }^{15}$ Implementation of the Strategic Action Plan for the Rehabilitation and Protection of the Black Sea, 1996-2001.
} 
overcome this difficulty, we use the same ratio of agricultural productivity to fishery productivity as in Romania $(a / \bar{S} f)$ and we obtain $\bar{S} f$ (Ukraine) $=14$. We note that the values of the agricultural productivity in each country largely exceed the values of the fishery productivity. This could partially explain the distribution of the labor force between the two sectors in each country.

Since we have the data on the fishery resource loss for each country $L$ in 1990 as well as on the total pollution stock $P$ in 1990 which is equal to $P_{1990}=63450$, we can obtain an evaluation of the fishery loss parameter:

$$
\begin{aligned}
\bar{S} \gamma(\text { Romania }) & =\frac{L}{P}=\frac{1156000}{63450}=18 \\
\bar{S} \gamma(\text { Ukraine }) & =\frac{L}{P}=\frac{21675000}{63450}=341
\end{aligned}
$$

Employment in the agricultural sector in each country is calculated by subtracting the number of fishermen from the aggregate, agricultural sector employment data (which includes agriculture, fishing, hunting activities) $N_{A}=N_{a}-N_{F}$. The underlying data are the following:

$N_{a}$ (Romania, 1999) $=3419000$

$N_{a}$ (Ukraine, 1999) $=4927000$

Source: IMF External Publications.

$N_{F}$ (Romania, 1999) $=117000$

Source: Black Sea Environmental Programme.

$N_{F}$ (Ukraine, estimated for 2001) $=45000$

Source: Food and Agriculture Organization, Fishery country profile, 2003.

$N_{A}$ (Romania, 1999)=3419000-117000=3302000

$N_{A}$ (Ukraine, 1999) $=4927000-45000=4882000$

\section{Appendix 6: Evaluation of Pollution Parameters}

It is impossible to evaluate precisely the regional stock of pollution in the Black Sea, because a sea's pollution widely differs spatially and seasonally. Therefore, the dynamic analysis of the pollution problem needs to be made at specific point sources of pollution, called hot spots. In order to construct the data on the pollution stock, we take into account some point in the sea between Romania and Ukraine. It is clear that this point is representative of the contribution of each country's pollution. Thus, it would be reasonable to add up the pollution stock of each country to calculate the total pollution stock at this point. We know the volume of water in the coastal 
waters of the Black Sea is $967 \mathrm{~km}^{3}$. The total coastal length of the sea is $4340 \mathrm{~km}$, the coastal line belonging to Romania being $225 \mathrm{~km}(5,2 \%)$ and that belonging to Ukraine being $1628 \mathrm{~km}(37,5 \%)$. Thus, we calculate the volume of water in the coastal areas of Romania $\left(0.052 \times 967=50 \mathrm{~km}^{3}\right)$ and Ukraine $(0.375 \times 967=367$ $\left.\mathrm{km}^{3}\right)$.

One of the most important factors causing nutritive pollution is total inorganic nitrogen, which is composed of nitrate $\left(\mathrm{NO}_{3}\right)$, nitrite $\left(\mathrm{NO}_{2}\right)$ and ammonium $\left(\mathrm{NH}_{4}\right)$. Some of the available data on the stock of total inorganic nitrogen are expressed in terms of micro moles. To transform these data into micro grams per litre, we multiply by $62 \mathrm{~g} / \mathrm{l}$ for nitrate, $18 \mathrm{~g} / \mathrm{l}$ for nitrite and $46 \mathrm{~g} / \mathrm{l}$ for ammonium. We multiply these concentrations per litre by the volume of water in each coastal water expressed in litres. To evaluate the pollution stock caused by agriculture, we divide the total stock by two.

The values of the total pollution stock $P$ (by only accounting for the agricultural emissions in the pollution stock) are summarized in the following:

Table IX. Total pollution stock $P$ (by only accounting for the agricultural emissions in the pollution stock)

\begin{tabular}{|l|l|}
\hline & $P \div 2$ \\
\hline 1979 & 49500 \\
\hline 1985 & 58125 \\
\hline 1990 & 63450 \\
\hline 1994 & 55060 \\
\hline 1995 & 40850 \\
\hline 1996 & 71950 \\
\hline 1997 & 215350 \\
\hline 1998 & 224925 \\
\hline 1999 & 199775 \\
\hline 2000 & 105825 \\
\hline
\end{tabular}

Source: The State of the Environment of the Black Sea: Pressures and Trends 1996-2000.

Several hot spots exist in Romania and Ukraine. The report on the State of the Environment of the Black Sea surveys emissions from three priority sources of pollution in Romania (South Constanta, South Eforie, Mangalia), whereas it considers ten priority sources in Ukraine (Odessa Pivnichni, Odessa Pivdenni, Illichevsk, Krasnoperekopsk, Kerch. Kamish Burunsky, Yalta, Sevastopol, Balaklava, Yevpatoriya, Gurzuf ). Some evaluations made by the Transboundary Diagnostic Analysis 
(1996) show that Romania's emissions are greater than those of Ukraine. Romania and Ukraine have an individual contribution of $27 \%$ and $12 \%$ of nitrogen to the Black Sea, respectively. Since the available data on point emission sources in the two countries do not reflect this situation, we use a transformation. We keep the emissions of Ukraine constant and multiply them by $\left(\frac{27}{12}=2,25\right)$ (the ratio suggested by the Transboundary Diagnostic Analysis, (1996)) to obtain the Romanian emissions. The emission levels of the countries before $\left(E_{B}\right)$ and after $\left(E_{A}\right)$ the transformation are summarized in the table below. The last calculus $(\div 2)$ reflects the transformation made on emissions in order to evaluate agricultural emissions in each country.

Table X. The emission levels of Romania before $\left(E_{B}\right)$ and after $\left(E_{A}\right)$ the transformation

\begin{tabular}{|l|l|l|}
\hline & $E_{B}$ & $E_{A}=E($ Ukraine $) \times 2,25 \div 2$ \\
\hline 1996 & 458 & 11201 \\
\hline 1997 & 1456 & 9840 \\
\hline 1998 & 1356 & 10042 \\
\hline 1999 & 1208 & 9337 \\
\hline 2000 & 844 & 8712 \\
\hline
\end{tabular}

Source: The State of the Environment of the Black Sea: Pressures and Trends 1996-2000. (E: total inputs from three priority sources of pollution in Romania, total inorganic nitrogen, tons/year)

Table XI. The emission levels of Ukraine

\begin{tabular}{|l|l|l|}
\hline & $E$ & $E \div 2$ \\
\hline 1996 & 9957 & 4978 \\
\hline 1997 & 8747 & 4373 \\
\hline 1998 & 8927 & 4463 \\
\hline 1999 & 8300 & 4150 \\
\hline 2000 & 7744 & 3872 \\
\hline
\end{tabular}

Source: The State of the Environment of the Black Sea: Pressures and Trends 1996-2000. (E: total inputs from ten priority sources of pollution in Ukraine, total inorganic nitrogen, tons/year)

The inverse of the emission parameter $\mu$ related to agricultural polluting activities is obtained from the following relationship:

$$
E=c+\frac{1}{\mu} A
$$


We evaluate by a crude simultaneous regression the fixed parameter as well as the emission parameter for the two countries. To achieve that, we use the following time-series for the values of emissions $E$ and agricultural value added levels $A$ from 1996 to 1999.

Table XII. Agricultural value added $A$ (constant 1995 US\$)

\begin{tabular}{|l|l|l|}
\hline$A$ & Romania & Ukraine \\
\hline 1996 & 5910000000 & 6090000000 \\
\hline 1997 & 6040000000 & 6030000000 \\
\hline 1998 & 5510000000 & 5360000000 \\
\hline 1999 & 5770000000 & 5130000000 \\
\hline
\end{tabular}

Source: World Bank Development Indicators.

We obtain the following values:

$$
\begin{aligned}
& E^{1}=8564+\frac{1}{3773584} A^{1} \\
& E^{2}=2991+\frac{1}{3773584} A^{2}
\end{aligned}
$$

The natural purification rate of pollution $k$ (or self-purification rate) is calculated from the following formula:

$$
\Longleftrightarrow P_{t+1}=(1-k)^{3} P_{t-2}+(1-k)^{2} E_{t-2}+(1-k) E_{t-1}+E_{t}
$$

We can write the evolution of the pollution stock between 1997 and 2000 (dates for which we have available data) in the following way:

$$
P_{2000}=(1-k)^{3} P_{1997}+(1-k)^{2} E_{1997}+(1-k) E_{1998}+E_{1999}
$$

Using the values for total emissions (of both countries) and pollution stocks, we obtain:

$$
105825=(1-k)^{3}(215350)+(1-k)^{2} 14213+(1-k) 14505+13487
$$

The resolution of this equation gives us one real solution, which is $k=0.30$. 